\title{
Video inspection of wells in open loop ground source heat pump systems in Norway.
}

\author{
Sondre Gjengedal, Randi K. Ramstad, Bernt Olav Hilmo, Bjørn Frengstad
}

\begin{abstract}
This paper presents results from video inspections of groundwater wells in Melhus and Elverum, in Norway. The method has identified iron bydroxides, bacterial growth and sand production as causes of clogging in different wells. Video inspection has proven itself a reliable, inexpensive and quick method for such investigations. The videos supply documentation for the building owner about the well condition. A video inspection should be incorporated as a standard part of the tender document and an integrated part of the maintenance routine. Finally, open loop GSHP and ATES system wells should be designed and manufactured with integrated video inspection options. This will ease the fault detection process and reduce maintenance costs of the system through the lifetime of the wells.
\end{abstract}

\section{INTRODUCTION}

Ground source heat is a renewable energy source that has a potential for increased use in Norway. Through the ORMEL project, the municipalities of Melhus and Elverum are evaluating their potential for further development, specifically with the open loop ground source heat pump systems (open loop GSHP systems). Melhus has utilized ground water for heating and cooling purposes since 1999, with good results, while Elverum is currently investing in such systems. Aquifer thermal energy storage systems (ATES systems) are vulnerable towards many of the same problems as GSHP systems, but will not be described further in this paper.

The typical open loop GSHP systems in Melhus and Elverum utilize an unconsolidated Quaternary sand and gravel aquifer as a heat source. The production well and injection well connect to the aquifer through customized screens, which withholds the sediments, while groundwater is allowed to flow freely into the wells. A submersible pump in the production well pumps groundwater through a secondary heat exchanger in the building, where a secondary fluid extracts heat. After heat extraction, the groundwater is re-injected to the aquifer in the injection well. Elverum currently has one such open loop GSHP system in operation. Melhus has nine such open loop systems, which utilize groundwater from the same aquifer. Of the nine systems, seven have injection wells, while the remaining two utilize the local drainage system for disposal of the return water.

Unlike domestic water works, there are no requirements regarding water quality in open loop GSHP system in Norway. Specified water quality guidelines do not exist and water quality issues are often disregarded or insufficiently emphasized during the planning and design phase of new projects. Lack of specialist input from a hydrogeologist often leads to insufficient aquifer investigation. The production wells or injection wells are seldom sufficiently tested before or after the construction phase. Insufficient instrumentation and lack of monitoring of the systems during operation also contribute to late discovery of fouling and other water quality issues. All of these factors are likely contributors to increased risks of problems caused by faulty design or inappropriate operational strategies. Similar findings are reported by Bakema (2001) and Banks (2012) who emphasize that most open loop problems are best dealt with through correct system design. 
Since 1999, a wide range of problems has occurred with the systems in Melhus. These problems often involve clogging of the well screens, either the production wells or the injection wells (Riise, 2015). Typically, the injection wells are more prone to clogging than the production wells. All of the seven injection wells in Melhus have had clogging issues. In comparison, clogging have been detected in two out of nine production wells. In Elverum, one planned open loop GSHP system was terminated because three of the four production wells showed severe clogging issues during the pre-investigation phase of the project. The active open loop GSHP system in Elverum has experienced clogging issues in one out of its two production wells. Common for the problems found in Melhus is a lack of monitoring of the wells during normal system operation. Only three of the systems monitor groundwater flow rates and only one system monitor pressure levels in the production well. None of the injection wells is monitored. As a result, the faults are seldom detected before the clogging have had time to develop and have become a sever problem.

Clogging problems can originate from a wide range of sources that yield similar symptoms, such as reduced groundwater flow rates through the system and increased pressure drops in the groundwater flow through the affected components (Bakema, 2001, Banks, 2012, Andersson et al., 1984). It is common to distinguish between mechanical, chemical or microbial causes. Mechanical clogging involves incrustations of sand, silt and other suspended particles, which fill the pore space in the soil and clog system components. Chemical clogging involves precipitation of particles, which in turn incrusts on system components. Microbial clogging, or biofouling, is caused by bacteria, which grow on system components. All of these complications require different cleaning or corrective approaches (Andersson et al., 1984) and there exists a need to distinguish between them. Flow rate and pressure monitoring is not capable of such distinctions. Consequently, such problems often call for investigations by means of water quality analysis or visual inspection of the affected area to identify the problem cause.

\section{EXAMPLES OF SUCCESSFUL VIDEO INSPECTIONS IN MELHUS AND ELVERUM}

Video inspection offers a familiar, hands-on, versatile and reliable approach. The method is common in domestic waterworks in Norway, England (Banks, 1992), the Netherlands (van Beek et al., 2017), USA (Jansen and LoCoco, 2007, Gorder, 1963) and most likely other countries. Similar methods are common in other industries such as buildings and constructions, roads and sewage systems where video inspection is a standardized part of any project. Today`s high-resolution color imaging cameras are capable of forward-looking and sideways-looking views with 360 degrees rotation and variable depth of focus. During the inspection, the video is shown in real-time on a monitor with a depth display. Some cameras, like the SupervisionTM SVR 140/SVC100 pan and tilt camera utilized in this study, are equipped with laser measuring tools, which for example enables measurement of screen slot openings in the well.

In groundwater wells, the usefulness of the method relies on the clarity of the water. Performing a flushing of the well and allowing particles to settle is in some cases recommended before the inspection, especially when inspecting new wells. Figure $1 \mathrm{~A}$ shows a new well that had been pumped for 14 days and where the pumping ended one week before the video inspection. The $1 \mathrm{~mm}$ screen slot openings were measured to confirm that the well was constructed in accordance to the specifications given in the tender document. The lodged sand grains and the clarity of the water indicate that the well was constructed in good agreement with the local soil conditions.

The clarity of the water might be a good indication of a well's current condition and an inspection without pre-flushing might be useful in itself. Figure 1B shows a production well in Elverum where the well screen is clogged by a biofilm of iron bacteria. This particular production well is less than 1 year old and had not yet been connected to the heat pump system. It was not flushed before the inspection. In this case the bacterial growth seems to favor specific parts of the screen and builds on the screen surface in a foam-like structure, effectively clogging some of the openings. These observations might not have been possible if the well was flushed before the inspection. Disinfection with chlorine and cleaning were necessary before the well could be connected to the system. 
Precipitated iron and manganese hydroxides is a common problem in Norwegian open loop systems (Riise, 2015). Often these particles accumulate in the injection well, after a journey through the rest of the system. But some examples of hydroxide precipitation is also found in production wells in Melhus. The production well screen in figure 1C is incrusted with precipitated iron hydroxides at the location of the pump inlet. The drawdown in the well was not monitored during operation and the water table was lowered below the suction inlet section of the pump. Mixture of air into the screen area allowed the chemical reaction to occur. Unlike the iron bacteria in figure 1B the precipitated hydroxides seem to evenly cover the screen slots. This well had functioned for 15 years before the problem was discovered and the well had to be abandoned because of faulty design.

The injection well in figure 1D is clogged by fine silt and clay particles. The particles originate from the sedimentary formation around the production well, where they are carried through the production well screen by the flow of water. The particles are unable to infiltrate back through the injection well screen and effectively clog the slots. Before the inspection the well was taken out of service and the suspended particles were allowed to settle. The picture shows some small particles of black manganese hydroxides still settling in the well. The problem was discovered 1.5-2 years after the plant was set in operation. The problem was solved by installing a filter on a part of the pipe section in the machinery room before reinjection of the groundwater back into the aquifer. The filter is regularly cleaned.
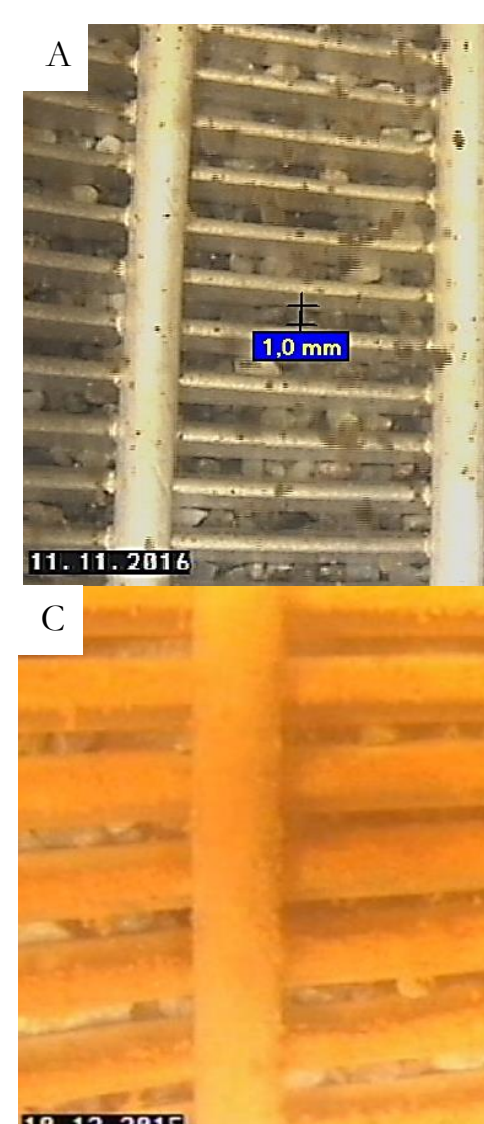
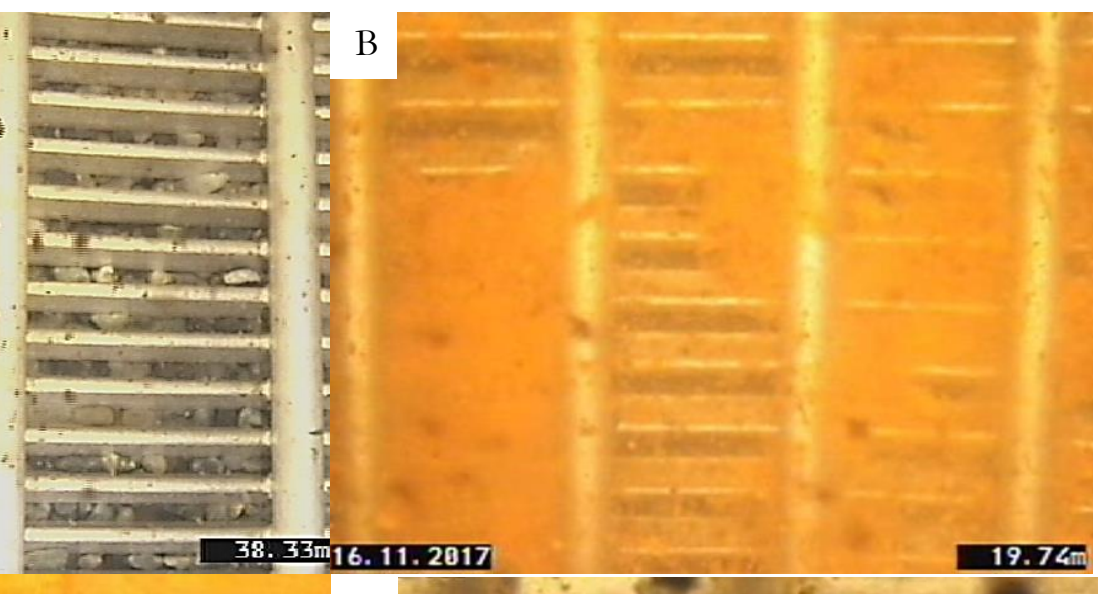

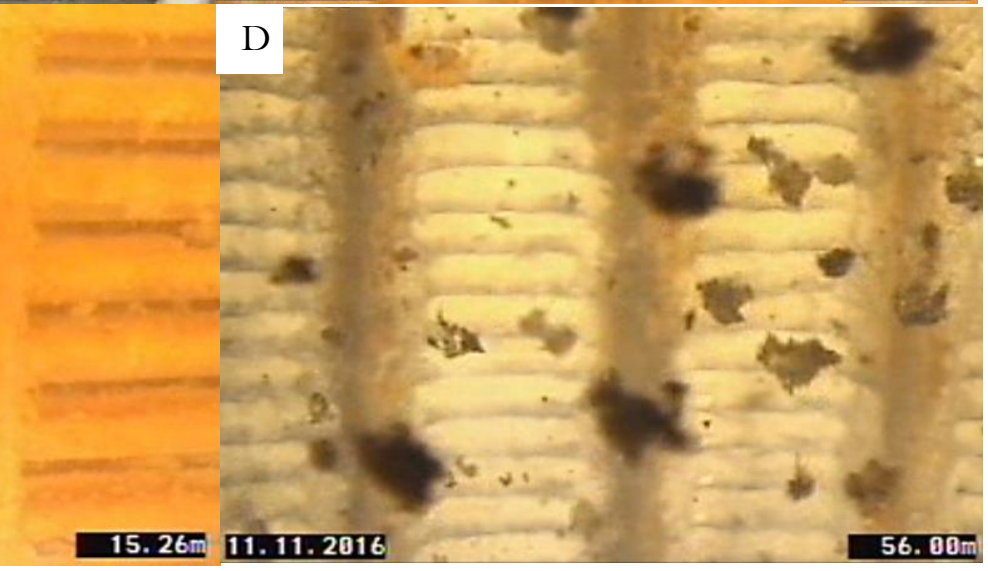

Figure 1 Video inspections of well screens. A: a newly constructed well in Melhus. The $1 \mathrm{~mm}$ slots were measured with a built-in laser tool. B: iron bacteria have infected this production well in Elverum. C: precipitated iron hydroxide incrustations on a production well screen in Melhus. D: sand and silt clogging an injection well screen in Melhus. Photos: Gjøvaag AS (part of the ORMEL project).

\section{BENEFITS, COST AND DRAWBACKS}

The presented video photos demonstrate the applicability of the method in open loop GSHP system wells. The investigation of newly constructed wells confirms that proper placement of screen, pump and pressure sensors are ensured and that the wells are constructed in agreement with the soil 
conditions and the tender documents. The method can identify location and type of debris, scale and biofilm deposits in clogged wells. New vs. old well conditions can be compared and such information supply vital knowledge to the system operator and allow planning of appropriate maintenance and corrective measures. The method has also been applied in real-time to direct rehabilitation operations in the well or to identify sand-production zones in the well while pumping is in progress (Jansen and LoCoco, 2007).

The cost of a video inspection is a function of the actual inspection time and transportation cost to the site. The actual inspection time required for a single well depends mainly on the well depth and clarity of the water. For example, the depth of the wells shown in figure 1A-1D are 40 (A), 22 (B), 24 (C) and 58 (D) meters, respectively. The time needed for the inspections ranged from 15 (A), 15 (B), 23 (C) and 30 (D) minutes, respectively. The total cost of the individual video inspections ranged from 5000-5700 NOK ( $\approx 520-590 €$ ) per well. By comparison, similar numbers have been reported by Banks (1992), where an average cost of 2500-6000 NOK ( $\approx 260-620 €)$ was registered in 1991.

A hydrogeologist can interpret the video during the inspection of the well or in the office afterwards. A digital copy of the video can also be sent to an expert (e.g. a microbiologist) for further evaluation.

The main drawbacks of the method involve the cost of preparing the wells for inspection. In Norway, the current open loop GSHP well designs generally follow the more traditional well designs applied for domestic drinking water purposes. Most of these wells are designed around the space required by the submersible pump, with minimum space available for other equipment. The camera utilized in this investigation required $90 \mathrm{~mm}$ diameter free space. Normally, the pump or injection pipe have to be dismantled and lifted out of the well for the camera to fit. The heat pump system must shut down during the video inspection, adding additional cost to the investigation.

If the well designs include enough space for a video camera while the pump and pipes are operating, the time needed and the over-all cost of the inspection is greatly reduced. A possible alternative would be to increase the well diameter sufficiently to give space for a camera along the side of the pump or injection pipe. An inspection "hatch" next

\section{New well design}
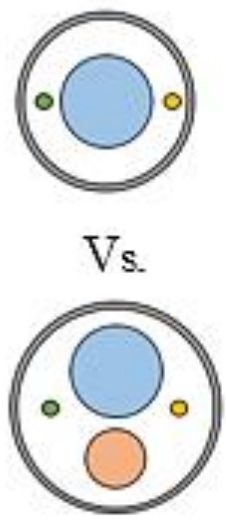

Production well
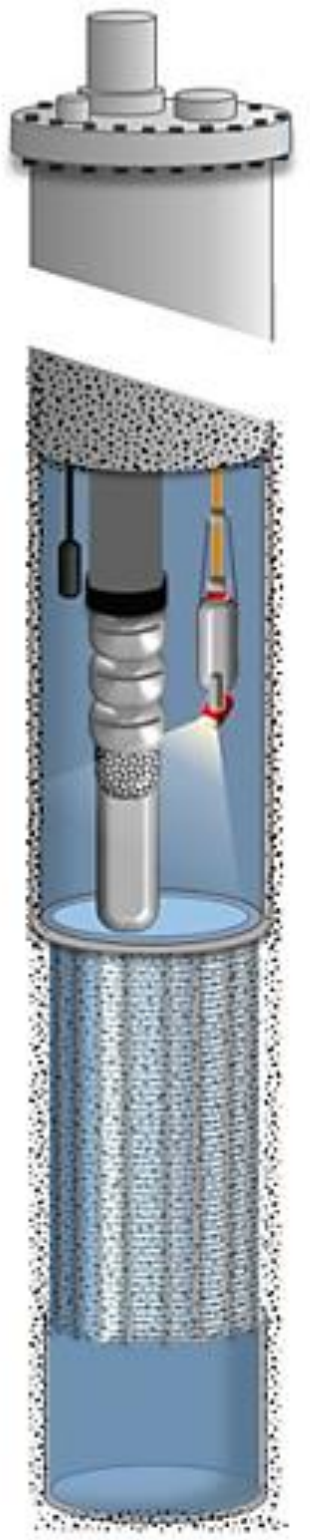

Traditional:

Pipe connection

Power cable

Pressure sensor

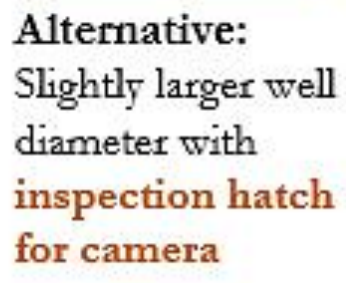

Injection well
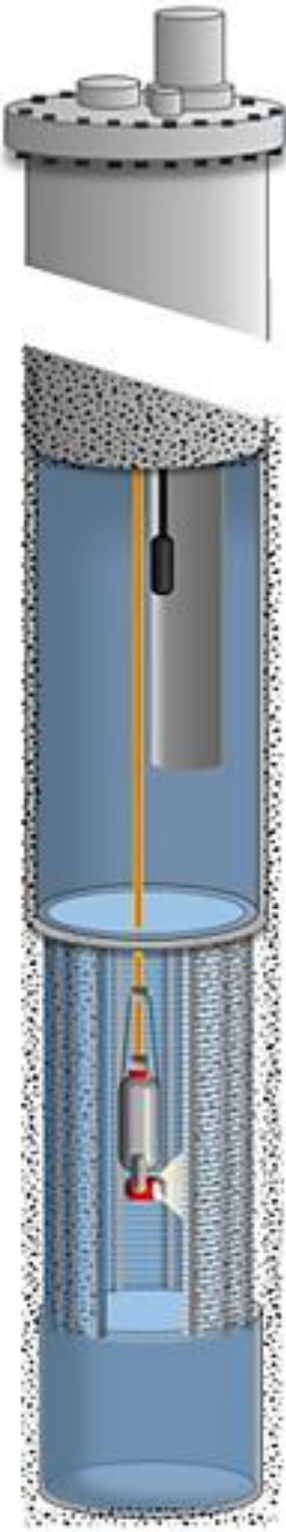

Figure 2 The traditional well design does not have space for a video camera. An alternative design that allows for real-time video inspection can reduce the over-all cost of fault detection. 
to the pipe connections is a potential technique. By installing the pump and injection pipe slightly offcenter, the additional well diameter needed for the camera might be minimized (figure 2). The video inspection can then be conducted during normal system operations and the actual well behaviors are observed live on the monitor while groundwater flows through the system. The increased installation cost due to a larger well diameter will be more than outweighed by the benefits of regular monitoring of the well conditions during the lifetime of the wells. In addition, a larger screen diameter would in most cases improve the well characteristics.

It might be argued that clogging problems also can be detected by measuring the specific flow or the pumping capacity. Although a reduction of the specific flow is easily understood by a hydrogeologist, a video presentation of the conditions in the well is a much stronger tool when trying to convince the well owner that a costly well rehabilitation is needed. If there is any doubt whether the well is installed according to order, a video inspection of the well can settle the dispute.

A record of routine video inspections from the wells were installed and onwards, will together with data on the performance of the open loop GSHP, be a strong tool for monitoring and documentation of the plant.

\section{CONCLUSION}

Video inspection of wells have proven to be a reliable, efficient and relatively low cost method for investigation of production wells and injection wells. A video inspection of the wells should be a standard part of the tender document in new open loop system and an integrated part of the maintenance routines. Open loop GSHP wells should be designed and manufactured with integrated video inspection options. This will ease the fault detection process and reduce maintenance costs of the system through the lifetime of the wells.

\section{ACKNOWLEDGMENTS}

The research project Optimal Utilization of groundwater for heating and cooling in Melhus and Elverum, the ORMEL project, is a cooperation between the municipalities of Melhus and Elverum, the Norwegian University of Science and Technology, Asplan Viak AS and the Geological Survey of Norway and with funding from the Norwegian Research Council. Erlend Skorstad at Gjøvaag AS performed the video inspection. We would like to thank all the involved institutions and persons for cooperation and financial contributions.

\section{REFERENCES}

Journal papers:

Gorder, Z. A. 1963. Television Inspection of a Gravel Pack Well. Journal - American Water Works Association, 55, 31-34. Van Beek, C., Hubeek, A., De La Loma Gonzalez, B. \& Stuyfzand, P. 2017. Chemical and mechanical clogging of groundwater abstraction wells at well field Heel, the Netherlands. Hydrogeology Journal, 25, 67-78.

Book:

Banks, D. 2012. An introduction to thermogeology : ground source heating and cooling, Chichester, Wiley-Blackwell.

Book section:

Jansen, J. \& LoCoco, J. J. 2007. Borehole Geophysics. In: Sterret, R. J. (ed.) Groundwater and Wells. 3 ed. New Brighton: JohnsonscreensTM.

State of the art reports:

Andersson, A.-C., Andersson, O. \& Gustafson, G. 1984. Brunnar: undersö̈kning, dimensionering, borrning, drift, Stockholm. Bakema, G. 2001. Well and borehole failures in UTESS. State of the art 2000. 2 ed. IF Technology bv.

Banks, D. 1992. Grunnvannsbronner : kontroll, vedlikehold, rehabilitering, Trondheim, Norges geologiske undersøkelse.

Thesis:

Riise, M. H. 2015. Praktisk guide for grunnvarmeanlegg basert på oppumpet grunnvann - Hydrogeologiske forundersokelser, etablering, drift og oppfolging med utgangspunkt $i$ erfaringer fra etablerte anlegg i Melhus sentrum. NTNU. 